\title{
Derechos socioprestacionales como categoría ideológica y estructural
}

\section{The socio-prestational rights as an ideological and structural category}

\author{
0 (우 \\ ALBERTO COLQUE LIZÁRRAGA \\ Tribunal Constitucional \\ (Lima, Perú) \\ Contacto: acolque@tc.gob.pe \\ https://orcid.org/0000-0002-6974-2139
}

\begin{abstract}
RESUMEN
El presente trabajo pretende abordar las categorías vinculadas a los derechos sociales y prestacionales, así como sus garantías. Con esa finalidad, se parte de la distinción entre derechos de primera y segunda generación, y se encuentra que su reconocimiento no se debió a criterios cronológicos ni estructurales sino ideológicos. De ese modo, en la finalidad igualitaria se halla el fundamento ideológico común a todos los derechos sociales, lo cual servirá para plantear una distinción definitiva entre derechos ideológicamente sociales y derechos estructuralmente prestacionales. Así, será posible trazar una intersección entre ambos grupos y postular los derechos socioprestacionales. Finalmente, se desarrolla el tema de
\end{abstract}


las garantías primarias y secundarias de estos derechos, señalando los modelos que se han planteado para su implementación y las dificultades empíricas que se han presentado.

Palabras clave: derechos socioprestacionales; derechos sociales; derechos prestacionales; garantías primarias; garantías secundarias.

\section{ABSTRACT}

The purpose of this paper is to address the categories related to social and benefit rights, as well as their guarantees. To this end, it starts from the distinction between first and second-generation rights and finds that their recognition was not due to chronological or structural criteria, but to ideological ones. Thus, the common ideological justification to all social rights is to be found in the egalitarian purpose, which will serve to establish a definitive distinction between ideologically social rights and welfare structural rights. Finally, the topic of primary and secondary guarantees of these rights is developed, pointing out the models that have been proposed for their implementation and the empirical difficulties that have arisen.

Key words: socio-prestational rights; social rights; benefit rights; primary guarantees; secondary guarantees.

Recibido: 13/04/2021 Aceptado: 16/04/2021

\section{INTRODUCCIÓN}

Por mucho tiempo, la clasificación de los derechos fundamentales, que distingue entre derechos de primera y segunda generación, o entre derechos de libertad (civiles y políticos) y derechos sociales, despertó el interés de gran parte de la doctrina, tanto para quienes plantean que no existiría alguna diferencia resaltante entre estos grupos, como para quienes encuentran en los derechos 
sociales una categoría que implica un tratamiento especialmente degradado por su aparente naturaleza prestacional.

Discurrir sobre los derechos sociales suele ser una tarea llena de dificultades, no solo por los obstáculos que desde la sociología del derecho llevan a cuestionar su efectividad, sino también por las ambigüedades teóricas que han surgido como consecuencia de un desarrollo más minucioso. Una de estas dificultades tiene relación con la distinción que existiría entre derechos sociales y derechos prestacionales, pues son categorías que suelen usarse de forma equivalente, sin reparar en que cada una de ellas nace de un criterio independiente de clasificación.

Esclarecer este panorama es necesario para salvar una confusión recurrente, tanto entre quienes niegan que exista alguna diferencia entre los derechos de primera y segunda generación, como entre quienes usan un criterio material o estructural para distinguirlos. Por otro lado, este esclarecimiento permitirá un tratamiento objetivo de las estrategias de garantía que plantean los derechos sociales, así como de las dificultades que se presentan en cada una de ellas.

\section{LAS GENERACIONES DE LOS DERECHOS HUMANOS}

En noviembre de 1977, El Correo de la UNESCO publicó un artículo escrito por el jurista checo Karel Vasak, en el cual se desarrollaba, por primera vez, el concepto de las tres generaciones de los derechos humanos, y se identificaba a los derechos civiles y políticos como derechos de primera generación; los derechos económicos, sociales y culturales como derechos de segunda generación; y se sugería, además, un posible reconocimiento de los derechos de solidaridad como derechos de tercera generación.

Dos años más tarde, Vasak redondeó su planteamiento en una conferencia brindada para el Instituto Internacional de Derechos 
Humanos en Estrasburgo, dando una visión de orden cronológico al reconocimiento por generaciones de los derechos humanos y vinculando los derechos de primera generación con el valor de libertad, los derechos de segunda generación con el valor de igualdad, y preguntándose si no deberían existir derechos producidos por la fraternidad de los hombres y su indispensable solidaridad que constituyan derechos de tercera generación (citado en Rabossi, 1997, pp. 43-44). La propuesta de Vasak fue determinante en desarrollos académicos posteriores que abrazaron esta forma de entender los derechos humanos, y es actualmente un recurso pedagógico indispensable.

Sin embargo, la distinción entre derechos civiles, políticos y sociales, así como la propuesta de su evolución progresiva, se remonta a 1950, año en que Thomas Humphrey Marshall sugiere estas características en Ciudadanía y clase social, relacionando los derechos humanos con la ampliación del concepto de ciudadanía. En ese sentido, Marshall (1997) refiere que «es posible asignar el período formativo en la vida de cada uno de ellos a un siglo diferente - los derechos civiles al siglo XVIII, los políticos al siglo XIX, y los sociales al siglo XX—» (p. 304). Sus planteamientos, reflejados en la propuesta de Vasak, justificarían hablar de «generaciones» en la aparición de los derechos humanos. No obstante, esta perspectiva se ha visto limitada en su aplicación desde un punto de vista histórico. Así, se tiene que, con algunas décadas de ventaja, Tom Bottomore (2007, p. 110), al realizar un análisis de la obra de Marshall, concluye que aquel parte de una concepción idealizada de los derechos de ciudadanía, al desconocer que estos son producto de procesos históricos contingentes y no teleológicos, así como que su desarrollo ha sido más irregular y más variable de lo que se podría esperar.

La crítica de Bottomore parece seguir la lógica del método genealógico propuesto por Michel Foucault (2004): 
[para quien] las fuerzas que están en juego en la historia no obedecen ni a un destino ni a una mecánica, sino al azar de la lucha. No se manifiestan como las formas sucesivas de una intención primordial; tampoco se presentan con la apariencia de un resultado. Aparecen siempre en el azar singular del acontecimiento (pp. 48-49).

Con base en lo anterior se puede concluir que un planteamiento generacional de aparición de los derechos humanos impide considerar y valorar determinadas luchas reivindicatorias y triunfos que, vistos desde los parámetros temporales establecidos por Marshall, resultarían anacrónicos. Tómese por ejemplo el caso del movimiento sufragista que se extendió hasta mediados del siglo XX y que logró el reconocimiento del derecho al voto de las mujeres. Si continuara una visión generacional de los derechos humanos, este derecho no podría considerarse como uno político ni, en consecuencia, de primera generación.

Una propuesta generacional de los derechos humanos «no permite apreciar el carácter con frecuencia simultáneo y complementario de las reivindicaciones de derechos civiles, políticos y sociales» (Pisarello, 2007, p. 35). Puede decirse, entonces, que el nacimiento de los derechos no está condicionado a un orden teleológico, sino que, parafraseando a Bobbio (1991, p. 18), los derechos humanos nacen cuando deben o cuando pueden nacer.

Aunque es cierto que Marshall (1997) no pretendió una contemplación rígida de estas generaciones, sino más bien que se traten estos períodos con una «flexibilidad razonable»(p. 304), resulta indudable que esta visión ha sido determinante para justificar la distinción entre derechos civiles, políticos y sociales, la cual ha tenido tanto éxito que ha sido abrazada incluso por el derecho internacional de los derechos humanos, con la adopción del Pacto Internacional de Derechos Civiles y Políticos y el Pacto Internacional de Derechos Económicos, Sociales y Culturales, ambos en 1966. 
Al respecto, es inevitable compartir el asombro de Liborio Hierro (2009) cuando refiere que "puede resultar sorprendente que una distinción surgida y consolidada por factores históricos tan contingentes penetrase tan profundamente como lo ha hecho en la teoría de los derechos contemporánea» (p. 168). Sobre todo porque su inclusión no ha sido metódica y, por el contrario, ha dado origen a una serie de confusiones respecto de la forma en la que deben estudiarse los derechos humanos.

Es posible que el germen de esta problemática se encuentre en la propia obra de Karel Vasak (1997), quien respecto de la naturaleza de los derechos humanos refiere que «los derechos de primera generación (civiles y políticos) se basan en el derecho a oponerse al Estado y los de la segunda generación (económicos, sociales y culturales) en el derecho a exigir al Estado» (p. 29). Esta afirmación, tan reiterada en la doctrina, parece sugerir que los derechos civiles y políticos se satisfacen a través de una conducta negativa o de no intervención del Estado, mientras que los derechos económicos, sociales y culturales requerirían de prestaciones por parte de este.

Sin embargo, recurrir a criterios materiales o estructurales para distinguir los derechos de primera y segunda generación tiende a fracasar, pues no se toma en cuenta un criterio estructural para la elaboración de estas categorías. Esto se demuestra al analizar derechos típicamente sociales como el derecho a la libertad sindical o el derecho a la huelga, los cuales se satisfacen por una conducta negativa del Estado antes que por prestaciones. En consecuencia, las generaciones pueden abrazar un conjunto estructuralmente heterogéneo de derechos, o como dice Pisarello (2007), «ni los derechos civiles y políticos pueden caracterizarse solo como derechos negativos, de abstención, ni los derechos sociales actúan siempre como derechos positivos, de prestación» (p. 60). 
Si el criterio de distinción entre derechos de primera y segunda generación no es estructural, como parecían sugerir Vasak y una gran parte de la doctrina, surge un problema respecto de su indeterminación, ya que si no existe un criterio de homogeneidad entre los derechos agrupados por generaciones, nada obsta para que en el futuro surjan más generaciones de derechos sin mayor sustento teórico. Esta es la preocupación de Martínez de Pisón (2004), quien señala que "las generaciones de derechos pueden ser infinitas si no hay algún tipo de control o supervisión» (p. 410). Esto último parece demostrarse en la actualidad, ya que algunos autores sugieren que existen las condiciones necesarias para reconocer una cuarta, quinta e incluso una sexta generación de derechos humanos (Rodríguez, 2015, p. 129).

Los controles que reclama Martínez de Pisón tienen relación con la intención de encontrar el elemento que vincule a todos los derechos dentro de la misma generación en la cual se les ha ubicado y, a la vez, establecer una suerte de control de calidad en la aparición de nuevas generaciones de derechos humanos. Por el momento, hemos visto que los criterios estrictamente cronológicos y estructurales no logran justificar que ahora hablemos de derechos de primera o segunda generación.

\section{GENERACIONES DE DERECHOS HUMANOS E IDEOLOGÍA}

Roberto González Álvarez (s. f.) rescata una anécdota relatada por Antônio Cançado Trindade, amigo de Karel Vasak, quien le pregunta a este último por la tesis de su conferencia, y obtiene como respuesta: «Ah, yo no tenía tiempo para preparar una exposición, en tanto se me ocurrió hacer alguna reflexión, y recordé la bandera francesa» (p. 1). Independientemente de si la anécdota es cierta o no, resulta evidente que Vasak se inspiró en los valores proclamados en la Revolución francesa para establecer sus planteamientos. 
De esta manera, los valores de libertad, igualdad y fraternidad se vinculan directamente con las tres generaciones de derechos humanos que propone, aunque sustituyendo la fraternidad por el valor de «solidaridad» para su proyecto de derechos de tercera generación.

Lógicamente, cada una de estas generaciones de derechos es producto de una determinada lucha, ya que «ninguno de estos derechos ha caído del cielo, sino que se trata de conquistas de movimientos revolucionarios» (Ferrajoli, 2008, p. 36). En ese sentido, los valores rescatados por Vasak, y ahora impresos en cada una de las generaciones de derechos, representan convicciones políticas y morales que, en un momento histórico determinado, motivaron su reivindicación. Por tal motivo, los derechos reconocidos no son neutrales, sino que indefectiblemente obedecen a una orientación ideológica determinada. Como dice García Belaúnde (1982), los derechos humanos «son ideologías en sentido amplio, porque reflejan intereses [...] de naciones, países o grupos de personas» (p. 114).

Esta naturaleza será común a todos los derechos pertenecientes a la misma generación, por ser productos de la misma gesta revolucionaria, ya que su contexto genético confiere a los derechos humanos unos perfiles ideológicos definidos (Pérez, 1991, p. 205). $\mathrm{Si}$ esto es cierto, es posible encontrar en los aspectos ideológicos los parámetros necesarios para justificar la existencia de las generaciones de derechos humanos. Efectivamente, según Antonio Peña Freire (2016, p. 260) existen dos estilos diferentes para definir a los derechos. Uno material, que define a los derechos a partir de su contenido, es decir, del objeto de las normas que forman su estructura normativa; y un criterio ideológico, según el cual pueden definirse los derechos como expresión de determinados valores y principios. 
Anteriormente, vimos que una distinción de los derechos de primera y segunda generación a partir de su estructura, es decir, tomando en cuenta el criterio material, es insuficiente, pues cada grupo contiene derechos estructuralmente heterogéneos. Ahora, al entender a los derechos desde un criterio ideológico, puede encontrarse un rasgo común en cada una de las generaciones, al margen del momento de su reconocimiento o la estructura que tengan.

$\mathrm{Al}$ hablar de generaciones de derechos humanos, se hace referencia a convicciones políticas y morales determinadas y al momento histórico en el cual se originaron. Sin embargo, estas ideologías son actuales y permanentes. Si entendemos con Fukuyama (1990) que «la ideología no se limita a las doctrinas políticas seculares y explícitas que asociamos habitualmente con el término, sino que también puede incluir a la religión, la cultura y el conjunto de valores morales subyacentes a cualquier sociedad» (p. 10), podemos estar de acuerdo en que los fundamentos ideológicos que dieron origen a las generaciones de derechos humanos no se circunscriben a una sola coyuntura, sino que se extienden en el tiempo.

Esto es relevante, pues solo así es posible salvar la objeción anacrónica que surge de la crítica de Bottomore a Marshall. Las generaciones de derechos son atemporales en la medida en que sus fundamentos ideológicos lo sean. Por ello, pueden reconocerse nuevos derechos de primera o segunda generación sin un estricto margen cronológico, ya que el derecho, entendido como práctica social y expresión axiológica, normativa e institucional, no se reduce a un único momento histórico (Sánchez, 2011, p. 19). De esta manera, también se supera el temor de una proliferación desmedida de generaciones de derechos humanos, por cuanto no surgen por el solo reconocimiento de nuevos derechos sino por la aparición de nuevas convicciones morales y políticas. 


\section{DERECHOS IDEOLÓGICAMENTE SOCIALES}

Si los derechos de segunda generación se encuentran imbuidos de una ideología determinada, comparten la misma motivación y los fundamentos políticos y morales. Los derechos sociales, por lo tanto, no están agrupados por una asociación histórica o estructural sino ideológica. De ahí que pueden existir derechos sociales estructuralmente negativos, como el derecho a la sindicalización o la huelga, y los derechos anacrónicos como el derecho social al agua. Pero si el parámetro que gobierna y da origen a los derechos sociales en general es su ideología común, ¿cuál es esta última?

Para Norberto Bobbio (1996, p. 151), los derechos sociales son una de las conquistas más clamorosas de los movimientos socialistas. Esta opinión es compartida tanto por Thomas Marshall, cuando ubica el origen de los derechos sociales en el siglo XX, como por Karel Vasak, cuando refiere que

por inspiración socialista y cristiana, con la revolución mejicana [sic] y, sobre todo, la revolución rusa, aparecieron los derechos del hombre formulados, también aquí, de modo global y en dimensión universal, al reconocerse los derechos económicos, sociales y culturales: se trata de los derechos de la igualdad (citado en Rabossi, 1997, p. 43).

Nótese que Vasak resalta estos derechos como derechos de igualdad en general, sin prestar atención a la revolución que los motivó. Esto podría deberse a que «la razón de ser de los derechos sociales como el derecho a la educación, el derecho al trabajo, el derecho a la salud, es una razón igualitaria» (Bobbio, 1996, p. 151), y por lo tanto esta motivación puede ser recogida como bandera por cualquier colectivo, independientemente de sus particularidades políticas.

Sin embargo, esta motivación no se vincula con la igualdad ante la ley o la igualdad de oportunidades, sino con la demanda de igualdad 
sustancial (Bobbio, 1993, p. 83). Por lo tanto, Bobbio (1996) prefiere hablar de igualitarismo y no solo de igualdad, entendiéndolo:

no como la utopía de una sociedad donde todos son iguales en todo sino como tendencia, por una parte, a exaltar más lo que convierte a los hombres en iguales respecto a lo que los convierte en desiguales, por otra, en la práctica, a favorecer las políticas que tienden a convertir en más iguales a los desiguales (p. 152).

A partir de la crítica que realizaron las doctrinas igualitarias contra el Estado liberal nacieron primigeniamente las peticiones de derechos sociales. Estas exigencias, como señalamos, son atemporales. De allí que incluso se presentan en los regímenes continuadores de la tradición liberal (Bobbio, 1993, p. 91). Esto último justifica que actualmente se sigan reconociendo nuevos derechos sociales, los cuales, al margen de su estructura, comparten una razón igualitaria junto con sus pares reconocidos a principios del siglo pasado.

Pueden reconocerse dos estrategias de los derechos sociales para alcanzar el fin igualitario. La primera se refiere a la reducción de la desigualdad material entre quienes tienen y quienes no tienen, que se materializa a través de prestaciones por parte del Estado. La segunda consiste en establecer condiciones suficientes que empoderen a determinados grupos sin recurrir a prestaciones, con la intención de hacerlos menos desiguales. Ejemplos de la primera estrategia pueden encontrarse en el reconocimiento de la mayoría de derechos prestacionales, como son el derecho a la salud o a la educación. Respecto de la segunda estrategia son ejemplos resaltantes los derechos a la libertad sindical y la huelga, que plantean un incremento en el poder de negociación de los trabajadores, lo cual es útil para encontrar mejores condiciones en términos de igualdad material. Es decir, aunque su naturaleza estructural no corresponde a una prestación, son ideológicamente sociales por tener una finalidad igualitaria. 
De hecho, la propia doctrina reconoce una razón igualitaria en estos derechos. Por ejemplo, respecto del derecho a la huelga, Blancas Bustamante (2011) ha dicho que «no hay duda de que la huelga posee todos estos significados, que la proyectan como un instrumento importante en orden a la consecución de objetivos de igualdad material, equilibrio en las relaciones capital-trabajo y participación en la vida económica-social» (p. 474). En el mismo sentido, el derecho a la libertad sindical es entendido como «un instrumento de desigualdad compensatoria o igualación en tanto constituye o permite constituir un contrapoder que limita, acota o compensa el poder económico del empleador» (Ermida, 2012, p. 36).

Puede decirse, entonces, que los términos «derechos de segunda generación»o «derechos sociales» hacen referencia al criterio ideológico común entre ellos, el cual se basa en una razón igualitaria. Esta condición no debe confundirse con el criterio material, que se refiere a la estructura de los derechos fundamentales. Derechos sociales son, por tanto, todos aquellos reconocidos con la finalidad de alcanzar condiciones igualitarias entre los ciudadanos, al margen de las estrategias que se utilicen.

\section{EL PROBLEMA DE LA DISTINCIÓN ESTRUCTURAL DE LOS DERECHOS DE PRIMERA Y SEGUNDA GENERACIÓN}

Desde que se plantearon las categorías de derechos de primera y segunda generación han surgido posiciones opuestas respecto de la relación que existe entre ambas, unas tienden a justificar la distinción que habría entre ellas y otras pretenden encontrar una naturaleza común. Sin embargo, como veremos a continuación, ambos puntos de vista confunden los criterios material e ideológico y se obtienen resultados contradictorios.

Por ejemplo, quienes defienden una identidad entre los derechos sociales y los derechos civiles y políticos parten de un criterio 
ideológico, pues desde este se puede hablar de derechos de primera y segunda generación. Luego trasladan el análisis a un criterio material para afirmar que en ambos grupos existen derechos con estructuras normativas diversas, y finalmente retornan al criterio ideológico para concluir que no habría diferencias estructurales entre derechos sociales y derechos civiles y políticos.

Como puede apreciarse, se llega a una generalización gratuita de la conclusión, pues si bien dentro de los derechos sociales pueden existir derechos que requieran obligaciones de no hacer, y dentro de los derechos civiles y políticos, derechos que requieran prestaciones, eso no quiere decir que estas características sean comunes a todos. Como refiere Antonio Peña (2016), «para que el argumento fuese relevante, habría que mostrar que todos los derechos de cada categoría ideológica comparten rasgos estructurales semejantes con todos los derechos de la otra» (p. 261). Estamos, en todo caso, ante una conclusión que a lo mucho puede tenerse por probable, pero que, por pretender abarcar los criterios material e ideológico a la vez, pierde certeza.

Por otro lado, quienes cuestionan que los derechos sociales tengan la misma naturaleza que los derechos civiles y políticos suelen referir que los primeros generan obligaciones positivas por parte del Estado, mientras que los segundos generan exclusivamente obligaciones negativas (Abramovich y Courtis, 2002, p. 21). Esto parece nacer del hecho de que la faceta más visible de los derechos sociales tiene relación con las obligaciones de hacer que estos implican y, en consecuencia, con la presunción de que, a pesar de que todos los derechos son costosos, los derechos sociales suelen costar más.

Esa afirmación, sin embargo, no es del todo definitiva, sino que se basa en una presunción. Aun así, es un aspecto considerado incluso por quienes defienden la identidad entre derechos de 
primera y segunda generación. Por ejemplo, Miguel Carbonell (2004) desarrolla una lúcida defensa de la identidad entre ambos tipos de derechos, aunque inmediatamente después afirma que «todo lo anterior no obsta para reconocer que los derechos sociales tienen un indudable componente prestacional, pues suponen la necesidad de que el Estado lleve a cabo un despliegue importante de actuaciones» (p. 322). En el mismo sentido, Víctor Abramovich y Christian Courtis (2002) refieren que «los derechos económicos, sociales y culturales también pueden ser caracterizados como un complejo de obligaciones positivas y negativas por parte del Estado, aunque en este caso las obligaciones positivas revistan una importancia simbólica mayor para identificarlos» (p. 25).

Si bien esto podría parecer suficiente para realizar una distinción entre derechos de primera y segunda generación, nótese de nuevo que estos autores no realizan una afirmación categórica sobre la naturaleza prestacional y el costo de los derechos sociales, sino solo relativa. Que todos los derechos sociales requieran prestaciones y sean más costosos que los civiles y políticos es solo una presunción que de ninguna manera puede justificar una distinción estructural entre ellos.

Entonces, queda claro que resulta infértil plantear una distinción estructural entre los derechos de primera y segunda generación, por el simple hecho de que estas categorías abarcan un conjunto bastante heterogéneo de derechos - estructuralmente hablando-. Por tal motivo, las discusiones sobre si existen diferencias estructurales entre los derechos sociales y los derechos civiles y políticos o no, o las discusiones acerca de cuál de estos resulta más costoso, no tendrán una respuesta más que relativa, pues parten de imponer un criterio material o estructural a categorías conformadas con un criterio ideológico. Si se pretende una respuesta certera a estos cuestionamientos, será necesario hacer un análisis desde el punto de vista material, es decir, sobre la base de la estructura de los 
derechos, prescindiendo de las clasificaciones de derechos por generaciones (o entendiéndolos como derechos sociales y derechos civiles y políticos) porque estas categorías son inevitablemente ideológicas.

\section{DERECHOS ESTRUCTURALMENTE PRESTACIONALES}

Una forma útil de distinguir la estructura de los derechos supone recurrir a los postulados de Luigi Ferrajoli (2004, p. 43), quien sostiene que los derechos subjetivos, y en específico los derechos fundamentales, consisten en expectativas negativas o positivas a las que corresponden obligaciones de prestación o prohibiciones de lesión, respectivamente. De esta forma, el sujeto encargado de cumplir con estas expectativas, que en el caso de los derechos fundamentales es el Estado, debe hacerlo a través de garantías positivas o negativas, según lo determine el tipo de expectativa a la que se refieran aquellos. Los derechos subjetivos son, en última instancia, expectativas, al ser en este caso el número gramatical de naturaleza contingente, pues un derecho subjetivo puede consistir en una sola expectativa o puede ser la suma de varias. Como refiere Ferrajoli (2013b), «los derechos subjetivos, y específicamente los derechos fundamentales, son habitualmente situaciones moleculares complejas» (p. 384).

En resumidas cuentas, un derecho subjetivo puede ser lo suficientemente genérico como para contener otros tantos derechos específicos, correspondientes cada uno a una expectativa determinada (negativa o positiva). Tómese el caso del derecho a la educación, que en esos términos contendría un conjunto de expectativas positivas y negativas. Así, incluiría, por ejemplo, el derecho a recibir una enseñanza gratuita (expectativa positiva), el derecho a elegir libremente el centro educativo o el derecho a no ser discriminado en este (expectativas negativas). 
Desde esa perspectiva es posible identificar derechos fundamentales que consistan exclusivamente en una o varias expectativas positivas. Son estos derechos a los que denominaremos derechos prestacionales, por ser satisfechos solo a través de una conducta positiva por parte del Estado. O, como refiere Prieto Sanchís (1995), son «aquellos derechos que en lugar de satisfacerse mediante una abstención del sujeto obligado, requieren por su parte una acción positiva que se traduce normalmente en la prestación de algún bien o servicio» (p. 12).

Los derechos prestacionales son una categoría que nace de un criterio material o estructural de clasificación de los derechos fundamentales $y$, por lo tanto, resulta impertinente referirse a la ideología que estos tendrían, pues «las técnicas prestacionales no pertenecen en exclusiva a alguna clase de derechos, sino que en general son aplicables a cualesquiera de los fines del Estado, incluso también a los derechos civiles y políticos» (Prieto, 1995, pp. 15-16). Un ejemplo de lo dicho lo encontramos en el derecho a la asistencia jurídica gratuita, que se encuentra reconocido en el Pacto Internacional de Derechos Civiles y Políticos. Por lo tanto, se trata de un derecho ajeno a una razón igualitaria o de igualdad material:

su origen histórico lo ubicamos en el concepto del due process of law del common law inglés, norma según la cual los individuos no deben ser privados de su vida, libertad o propiedad sin que previamente se les brinde una oportunidad de defensa judicial efectiva (Ortiz, 2008, p. 403).

Es, por lo tanto, un derecho íntimamente vinculado al derecho a la tutela jurisdiccional efectiva y, sin embargo, es ante todo un derecho prestacional, pues crea expectativas positivas que el Estado debe garantizar, no para cumplir fines igualitarios, sino de libertad. 


\section{GARANTÍA DE LOS DERECHOS SOCIALES PRESTACIONALES}

Luego de distinguir, a partir de criterios independientes, los grupos de derechos sociales y prestacionales, no queda mucho por decir respecto de esta nueva categoría de derechos «sociales prestacionales» que no se pueda deducir del desarrollo realizado. Los derechos socioprestacionales, como también podemos llamarlos, representan una intersección del conjunto ideológicamente homogéneo de derechos sociales y el conjunto estructuralmente homogéneo de los derechos prestacionales. En ese sentido, derechos socioprestacionales son todos aquellos que consisten en expectativas positivas y que a la vez tengan una razón igualitaria. Sin embargo, para evitar que se generen dificultades innecesarias con la utilización de este neologismo, a partir de ahora nos referiremos a ellos simplemente como derechos sociales, ya que es la forma que la doctrina suele utilizar para aludir a ellos.

Corresponde ahora establecer las formas en las que estos derechos pueden ser garantizados. Como ya se mencionó, los derechos subjetivos consisten en expectativas positivas (de prestación) o negativas (de no lesión). Estas, a la vez, generan obligaciones que podemos denominar garantías (Ferrajoli, 2008, p. 63). Las garantías son negativas o positivas, según lo determine la naturaleza del derecho.

Ferrajoli (2008, p. 64) distingue dos clases de garantías. Llama garantías primarias o sustanciales a las que consisten en obligaciones o prohibiciones que corresponden a los derechos subjetivos garantizados, y denomina garantías secundarias o jurisdiccionales a las obligaciones de los órganos judiciales de aplicar la sanción o de declarar la nulidad cuando se constaten actos ilícitos o inválidos que violen los derechos subjetivos y, con ellos, las correspondientes garantías primarias. En otras palabras, mientras las garantías primarias representan deberes consistentes en prohibiciones o prestaciones, las secundarias son obligaciones de anulación o condena 
por defectos de las garantías primarias (Ferrajoli, 2013a, p. 769), y tienen, en todo caso, una naturaleza subsidiaria respecto de ellas.

En el caso de los derechos sociales, las garantías primarias estarán referidas a los desarrollos legales que se hagan de cláusulas constitucionales que reconozcan estos derechos, a las políticas públicas, a los programas sociales y a las instituciones capaces de proveer las prestaciones, como escuelas, hospitales, seguro social, etc. Por su parte, las garantías secundarias o jurisdiccionales se presentan ante el incumplimiento de las prestaciones o por la falta de implementación de garantías primarias en general. En el caso de los derechos sociales, tanto sus garantías primarias como secundarias presentan algunos problemas como consecuencia de sostenerse exclusivamente en expectativas positivas.

Respecto de las garantías primarias surge un problema económico, pues el cumplimiento de las prestaciones a las que está obligado el Estado estará vinculado a que existan los recursos suficientes para proveerlas. No debe perderse de vista que el reconocimiento de los derechos sociales en las constituciones es solo un acto simbólico si no se establecen y cumplen las garantías primarias. Al respecto, la evidencia empírica ha demostrado que el solo hecho de reconocer constitucionalmente derechos sociales no incide de modo directo en el desempeño social del Estado (Edwards y García, 2015, p. 102). Por otro lado, en cuanto a las garantías secundarias, surge el problema de la competencia política de los jueces para tomar decisiones sobre partidas presupuestarias, ya que esto afectaría la separación de poderes. Mientras más activista sea una decisión judicial referida a prestaciones, más afectación existirá a la competencia del órgano político correspondiente.

El problema es doble en estos supuestos, pues como consecuencia de lo anterior, cuando se trata de decidir sobre el otorgamiento de prestaciones, «los jueces suelen considerar tales cuestiones como propias de la competencia de los órganos políticos del sistema» 
(Abramovich y Courtis, 2002, p. 127). En el caso Lindiwe Mazibuko y otros vs. Ciudad de Johannesburgo y otros, por ejemplo, la Corte Constitucional de Sudáfrica, frente a la pretensión de vulneración del derecho fundamental al agua por la instalación de medidores para determinar el pago de su uso en exceso, resolvió que no podía deducirse de la redacción constitucional una cantidad específica de agua, por lo que no le correspondía a ninguna corte determinar esa cantidad, al ser más bien un asunto de política pública que debía dejarse en manos del gobierno.

Los problemas enunciados se verán influidos por la dimensión que se dé a las garantías de los derechos sociales, pudiendo construirse modelos de amplias y universales garantías primarias, y débiles garantías secundarias o modelos en los que las garantías primarias se otorgan de forma focalizada y las garantías secundarias tengan un mayor protagonismo. A fin de entender mejor estos modelos, es pertinente referirnos a la universalidad como característica de los derechos sociales fundamentales.

\section{UNIVERSALIDAD DE LOS DERECHOS SOCIALES}

Según la doctrina predominante, la universalidad es una característica esencial en los derechos fundamentales. Cuando se habla de ella, suele entenderse una condición que abarca a todos los sujetos del género humano. De ahí que, si un derecho excluye a determinados grupos de personas, no se le considera como derecho fundamental por no ser universal. Sobre ello, Pedro Nikken (1994) menciona que «una de las características resaltantes del mundo contemporáneo es el reconocimiento de que todo ser humano, por el hecho de serlo, es titular de derechos fundamentales que la sociedad no puede arrebatarle lícitamente» (p. 16).

Sin embargo, una concepción de la universalidad como esa solo puede ser valorada dentro de un enfoque filosófico moral, por 
constituir un anhelo para las normas jurídicas antes que la descripción de la realidad dogmática. La universalidad, así entendida, resulta inútil cuando se trata de estudiar los ordenamientos jurídicos, pues estos se encuentran lejos de reconocer que la titularidad de todos los derechos fundamentales le corresponde a toda persona, solo por su condición de ser humano. Prueba de ello es que aun en los ordenamientos jurídicos más progresistas, algunos derechos fundamentales se encuentran reservados para determinados grupos, que, aunque bastante amplios, están lejos de una universalidad como la descrita.

Para Luigi Ferrajoli (2004), la universalidad, vinculada a la teoría de los derechos fundamentales, está determinada por tres estatus: el de persona, el de ciudadano y el de capaz de obrar. En esa línea, «son derechos fundamentales todos aquellos derechos subjetivos que corresponden universalmente a todos los seres humanos en cuanto dotados del estatus de personas, de ciudadanos o personas con capacidad de obrar» (Ferrajoli, 2004, p. 37). Esto cobra sentido si se toma en cuenta que existen ordenamientos jurídicos que condicionan el disfrute de los derechos fundamentales a estas tres categorías. Por ejemplo, actualmente es poco probable que exista una constitución que limite el derecho a la vida solo a sus ciudadanos o los mayores de edad, pues la mayoría de ellas otorga este derecho a todas las personas. Por otro lado, un derecho como la participación política suele no estar reconocido a todas las personas, sino solo a los ciudadanos de un determinado país. Ambos derechos son universales en sus términos: el derecho a la vida es universal respecto del estatus de personas y el derecho a la participación política es universal respecto del estatus de ciudadano.

Tomando en cuenta esto, queda claro que los derechos sociales pueden garantizarse sobre la base de estos tres estatus, sin que se comprometa su condición de derecho fundamental. Sin embargo, si bien en algunos estados de bienestar los derechos sociales han 
llegado a garantizarse de forma tal que todas las personas o los ciudadanos, capaces de obrar o no, pueden disfrutar de ellos sin más exigencia que su condición como tales, lo cierto es que en la mayoría de países, sobre todo los que se encuentran en vías de desarrollo, se han adoptado estrategias de focalización para proveerlos, debido a la limitación de sus recursos. De esta forma, en esos países los derechos sociales solo pueden ser exigidos por los más desventajados.

Estas estrategias de focalización podrían sugerir que en los países que las aplican, los derechos sociales no serían derechos fundamentales, pues para ser titular de ellos se requeriría de un estatus adicional, además del de persona, ciudadano o capaz de obrar. Ferrajoli (2013a, p. 688), atento a estos detalles, plantea la existencia de estatus particulares y contingentes, de los cuales todos, en algún momento, podremos ser titulares, como por ejemplo la condición de trabajador, de imputado, de cónyuge, de enfermo, etc. Estas condiciones pueden justificar la existencia de derechos fundamentales que se reserven a personas o ciudadanos, capaces de obrar o no, que requieran de un estatus específico adicional. Ferrajoli (2013c) resume la situación en la siguiente tesis: «son derechos fundamentales todos los derechos pertenecientes a todos en cuanto personas o ciudadanos y/o capaces de obrar, incluso si dotados de otros estatus específicos» (p. 609).

Por ese motivo, los derechos sociales que son provistos por los Estados a través de técnicas de focalización mantienen su condición de derechos universales, solo si se considera para su garantía la existencia de un estatus contingente adicional. Este nuevo estatus estará determinado por la situación de pobreza en la que se encuentre una parte de la población, y a la que todos podrían llegar en algún momento. Entonces, podemos concluir que, en estos casos, además de los estatus de persona, de ciudadano y de capaz de obrar, existiría un estatus contingente de menesterosidad. 


\section{MODELOS DE GARANTÍA DE LOS DERECHOS SOCIALES}

Fernando Atria (2004, p. 32) distingue dos concepciones de derechos sociales: una liberal, vinculada a la eliminación de la pobreza, y otra socialdemócrata, que busca eliminar la desigualdad. La concepción liberal se concentra en estrategias de focalización de la garantía de los derechos sociales, tomando en cuenta los grupos vulnerables y estableciendo prestaciones mínimas y subsidiarias. Por otro lado, la concepción socialdemócrata implica una garantía universal y gratuita en términos de igualdad.

\subsection{Modelo socialdemócrata}

Atria defiende una concepción socialdemócrata de los derechos sociales. En tal sentido, sigue la línea de Thomas Marshall (1997, p. 323), quien refiere que estos derechos son una extensión de la ciudadanía. Por lo tanto, para aquel los derechos sociales «configuran una forma diferente de comunidad, una en que la comunidad como un todo se preocupa del bienestar de cada uno de sus miembros» (Atria, 2004, p. 44). Esta forma de entenderlos lo lleva a cuestionar su reconocimiento como derechos jurídicamente subjetivos, en el sentido de que, al poder ser exigidos individualmente, se trastocaría la intención de colaboración entre todos los miembros de la sociedad, que es justamente lo que sustenta a estos derechos. En palabras de Atria (2004):

Lo que llega al tribunal no es un derecho social, no puede ser un derecho social, sino una demanda privada, que expresa ya no la idea de una forma superior de comunidad sino la negación de esta: la pretensión del demandante de que su interés sea atendido, aun a costa del interés de los demás (p. 46).

Si los derechos sociales son una responsabilidad de todos, como plantea Atria, no es posible que su satisfacción se deje al arbitrio 
de demandas individuales. Esto plantea una distinción entre el mercado y la esfera pública caracterizada por los derechos sociales, pues:

lo que caracteriza al mercado como criterio de distribución es que el hecho de que cada uno obtenga lo que quiere en el mercado es un problema privado de él, mientras que el hecho de que una persona reciba aquello a lo que tiene derecho es un problema público, de todos (Atria, Larraín, Benavente, Couso y Joignant, 2013, p. 181).

Por consiguiente, la provisión de los derechos sociales debe atender a todos por igual, en la medida en que tienen el mismo derecho. En ese sentido, no se trata de una situación que deba dejarse al arbitrio del mercado. Para ello, Atria recurre a una universalización de los derechos sociales que descartaría la exigencia de un estatus de menesterosidad para su disfrute.

En el lenguaje teórico de Ferrajoli, podría entenderse que Atria propone que los derechos sociales deben satisfacerse exclusivamente a través de garantías primarias, pues, como señala el filósofo florentino, «menos problemáticas son las garantías sociales secundarias, una vez introducidas las garantías primarias [...] y por tanto la posibilidad de detectar y eliminar sus posibles violaciones» (Ferrajoli, 2013b, p. 388). Desde ese punto de vista, la propuesta de Atria representaría un sistema en el que las garantías primarias de los derechos sociales se encuentran ampliamente cubiertas, dejando un corto espacio a la exigibilidad jurisdiccional, por el incumplimiento de estas. Entendiendo que se plantean garantías primarias seguras y eficaces, no tendría sentido hablar de garantías secundarias, al haberse cumplido de forma universal las expectativas positivas de los derechos sociales. 


\subsection{Modelo Liberal}

Fernando Atria (2004) menciona que «los derechos sociales en clave liberal son concebidos como una especie de seguro que cada agente toma para precaverse de la posibilidad de encontrarse descubierto y necesitado» (p. 31). Es decir, desde la perspectiva liberal, los derechos sociales son entendidos como derechos subsidiarios. Robert Alexy (2007), en la misma línea, los define como «derechos del individuo frente al Estado a algo que -si el individuo tuviera los medios financieros suficientes, y si encontrase en el mercado una oferta suficiente- podría obtener también de los particulares» (p. 443). La propuesta de este último supone que en general los bienes y los servicios son preferiblemente asignados por el mercado, y solo cuando faltan medios financieros o no existe una oferta suficiente debe hacerse presente el Estado.

Alexy refiere que el argumento principal a favor de los derechos sociales es uno de libertad, para ello se basa en dos tesis. La primera señala que la libertad jurídica no tiene ningún valor si no existe una libertad fáctica. Es decir, la libertad jurídica que habilita a una persona a realizar una acción o no, no tendrá valor alguno si esta no posee los bienes materiales o espirituales suficientes para poder ejercerla. La segunda refiere que, bajo las condiciones de la sociedad industrial moderna, la libertad fáctica de un gran número de personas no está dentro de un ámbito vital dominado por ellas, sino que requieren de la intervención del Estado para poder alcanzarla (Alexy, 2007, p. 447).

El reconocimiento de los derechos sociales como derechos fundamentales implica el aseguramiento de la libertad fáctica de las personas, sin la cual las libertades jurídicas se convertirían en meras fórmulas vacías o, en términos de Riccardo Guastini (2001, p. 220), en meros derechos sobre el papel, y no verdaderos derechos. Si el fundamento principal de los derechos sociales es la igualdad de oportunidades para alcanzar la libertad fáctica, y no una 
igualdad material general, es posible concluir que los derechos sociales aseguran solo los mínimos necesarios para alcanzar dicha libertad.

De esta manera, los derechos sociales tendrían dos rasgos definidos: ser subsidiarios y ser mínimos. Son subsidiarios, pues se refieren a bienes y servicios condicionados a la ausencia de capacidad para adquirirlos por los propios medios en el mercado, y son mínimos, pues su finalidad es proveer un mínimo de satisfacción de necesidades básicas suficientes para poder ejercer la libertad jurídica. Esta fórmula recuerda la intención de Hayek (2006) de

asegurar a todos una renta mínima, o un nivel por debajo del cual nadie descienda cuando no puede proveer por sí solo, no solo es una protección absolutamente legítima contra riesgos comunes a todos, sino una tarea necesaria de la Gran Sociedad en la que el individuo no puede ya apoyarse en los miembros del pequeño grupo específico en que ha nacido (p. 422).

Nótese que Hayek no solo reconoce la naturaleza subsidiaria y mínima de las prestaciones que el Estado debe otorgar a título de derechos sociales, sino que a la vez reconoce que los titulares de estas deben poseer un estatus particular y contingente como consecuencia de riesgos comunes a todos los miembros de la sociedad. Es decir, un estatus adicional al de persona, de ciudadano o de capaz de obrar, al que hemos denominado estatus de menesterosidad.

\section{OBSTÁCULOS EN LA IMPLEMENTACIÓN DE LOS DERECHOS SOCIALES}

La propuesta de Fernando Atria es impecable desde el enfoque de la filosofía de la justicia, pues no cabe duda de que la universalización de los derechos sociales cumple en mayor grado su razón igualitaria. Se deja de lado la lógica del mercado, por la que cada 
uno recibe lo que quiere y puede pagar (y quien no puede, recibe el mínimo), y se adopta lo que Atria (2012, pp. 70-71) denomina la «descomodificación», según la cual la distribución de los bienes se realiza conforme a la lógica universalista de los derechos sociales. Institucionalmente, esta forma de organizar la provisión de los derechos sociales permite justificar la existencia del Estado de bienestar, en el que «suele haber sistemas públicos de educación o salud que en general no admiten, o admiten solo limitadamente, libertad de elección» (Atria et al., 2013, p. 178).

Aunque podemos calificar la propuesta socialdemócrata como justa, desde el plano de la sociología del derecho, todo parece indicar que es ineficaz o, por lo menos, que su implementación traería algunos efectos contraproducentes para la misma razón igualitaria que los derechos sociales pretenden alcanzar. Por ejemplo, sobre la discusión de la implementación de la gratuidad de la educación superior en Chile (en los términos defendidos por Fernando Atria), se ha dicho que su provisión universal y gratuita generaría un desbalance fiscal, y aunque también tendría efectos en la reducción de la desigualdad, estos serían menores que los de un modelo focalizado (Beyer y Cox, 2011, p. 1).

Fernando Atria (2012), sin embargo, parece darle más importancia a una razón igualitaria ideal antes que a los problemas que se presentarían con su implementación fáctica. $\mathrm{O}$, como él dice, «el problema está en los principios generales, no en su aplicación», y agrega:

Organizar el gasto público bajo el principio de focalización es una manera de introducir al sistema educacional (y de salud, y de seguridad social, etc.) un principio de segregación que hará que los pobres reciban algo que ni siquiera tiene la pretensión de estar al mismo nivel que lo que reciben los ricos (p. 66). 
Si bien todos podemos compartir la intención de la propuesta y conceder que se trata de una que asegura en mayor grado el fin igualitario de los derechos sociales, no podemos dejar de lado su factibilidad, que parece postergarse cuando se trata de una implementación universal.

Por otro lado, respecto del modelo liberal también se presentan problemas en la garantía de los derechos sociales. Así, se tiene que, según las investigaciones del profesor David Landau (2015), en la mayor parte del mundo la aplicación de estos derechos incrementa los beneficios concedidos a los grupos de las clases más altas, antes que otorgarlos a los grupos sociales con mayor necesidad, ya que, a diferencia de ellos, la clase media tiene mayor posibilidad de conocer sus derechos y poder manejar los costos y las particularidades del sistema jurídico.

Debe advertirse, sin embargo, que estos problemas surgen de los intentos de universalizar los derechos sociales sin asumir las responsabilidades del criterio socialdemócrata. Es decir, de pretender una garantía universal de estos derechos a través de la vía jurisdiccional, dejando intactas las garantías primarias en su lógica focalizadora. Esta estrategia se limita a eliminar el estatus de menesterosidad como exigencia para ser titular de derechos sociales y habilita a cualquier persona para reclamar jurisdiccionalmente una prestación del Estado. Sus efectos son totalmente contraproducentes, pues la focalización establecida por las garantías primarias termina siendo aprovechada por quienes pueden acceder con mayor facilidad a las garantías secundarias y, en consecuencia, las cortes tendrán una mayor tendencia a proteger los derechos de los funcionarios públicos pensionados o subsidiar viviendas para la gente de la clase media antes que a transformar las vidas de los grupos marginados (Landau, 2015). Esto debido a que la clase media tiene mayor facilidad de acceso a las vías jurisdiccionales, ya sea por poseer los recursos suficientes como para asumir los costos 
de un proceso judicial, o por el simple hecho de estar en mejores condiciones de conocer sus derechos, a diferencia de la población más vulnerable.

\section{REFLEXIONES FINALES}

La distinción entre derechos de primera y segunda generación, o entre derechos de libertad (civiles y políticos) y derechos sociales, no obedece a un criterio estrictamente cronológico o estructural, sino que se basa en las convicciones políticas y morales que les dieron origen. En el caso de los derechos sociales, su carácter distintivo es un fin igualitario, pues a través de estos se pretende alcanzar ciertos grados de igualdad material para los ciudadanos.

Una visión de los aspectos ideológicos de los derechos sociales permite distinguirlos de la categoría de derechos prestacionales, la cual se basa en aspectos estructurales que exigen una prestación estatal para su garantía. Es, por lo tanto, ajena a cualquier tipo de convicción política o moral. Esto nos permite diferenciar dos grupos: uno de derechos ideológicamente sociales y otro de derechos estructuralmente prestacionales, ambos independientes, pero que pueden encontrarse para dar origen a un grupo de derechos que estén orientados por una ideología igualitaria y a la vez asuman una estrategia prestacional para su garantía, a los que bien puede denominarse socioprestacionales.

Los derechos sociales han sido garantizados a través de dos estrategias bastante opuestas. Una estrategia liberal que, en última instancia, se concentra en la reducción de la pobreza a través de una provisión focalizada de las prestaciones, y una estrategia socialdemócrata que busca reducir la desigualdad a través de una provisión universal de las prestaciones, al margen del estatus de menesterosidad de los ciudadanos. La estrategia socialdemócrata es más justa en términos filosófico-morales, pero ineficaz en términos 
sociológicos. En cambio, la estrategia liberal resulta eficaz en términos sociológicos, pero menos deferente al fin igualitario frente a la estrategia socialdemócrata.

La implementación de la estrategia liberal ha encontrado como obstáculo una tendencia que pretende la universalización de los derechos sociales sin asumir los costos de la estrategia socialdemócrata. En tal sentido, se elimina su provisión focalizada, manteniéndolos como derechos subjetivos para que sean reclamados por todos, incluso por quienes se encuentran en mejor condición económica. Esto ha generado un sistema que resulta justo solo en intenciones y apariencias. La evidencia demuestra que se ha transformado en una herramienta para mantener las desigualdades entre las clases sociales.

El establecimiento de una forma coherente de provisión de las prestaciones sociales requiere reconsiderar la estrategia liberal, retomando como presupuesto el estatus de menesterosidad, que es necesario para que los recursos, naturalmente escasos, sean destinados a quienes realmente los necesitan. Frente a propuestas «más justas» en términos morales, como la estrategia socialdemócrata, surge el dilema de elegir entre lo justo y lo eficaz, entre la realidad y las buenas intenciones. No debe olvidarse, sin embargo, que de buenas intenciones está empedrado el camino al infierno.

\section{REFERENCIAS}

Abramovich, V. y Courtis, C. (2002). Los derechos sociales como derechos exigibles. Trotta.

Alexy, R. (2007). Teoría de los derechos fundamentales. Centro de Estudios Políticos y Constitucionales.

Atria, F. (2004). ¿Existen derechos sociales? Discusiones, (4), 15-59. 
Atria, F. (2012). Observaciones sobre el comentario del profesor Julio Verdugo. Anuario de Derecho Público, (1), 62-74.

Atria, F., Larraín, G., Benavente, J. M., Couso, J. y Joignant, A. (2013). El otro modelo. Del orden neoliberal al régimen de lo público. Debate.

Beyer, H. y Cox, L. (2011). Gratuidad de la educación superior: una política regresiva. Puntos de Referencia, (337), 1-8. https://www. cepchile.cl/cep/site/docs/20160304/20160304095625/pder337_ LCox_HBeyer.pdf

Blancas, C. (2011). La cláusula del Estado social en la Constitución. Análisis de los derechos fundamentales laborales. Fondo Editorial de la Pontificia Universidad Católica del Perú.

Bobbio, N. (1991). El tiempo de los derechos. Sistema.

Bobbio, N. (1993). Igualdad y libertad. Paidós.

Bobbio, N. (1996). Derecha e izquierda. Taurus.

Bottomore, T. (2007). Ciudadanía y clase social, cuarenta años después. En Marshall, T. H. y Bottomore, T., Ciudadanía y clase social (pp. 85-138). Alianza Editorial.

Carbonell, M. (2004). La garantía de los derechos sociales en la teoría de Luigi Ferrajoli. Jurídica, (34), 301-333.

Edwards, S. y García, Á. (2015). Educación y derechos constitucionales. Estudios Públicos, (139), 67-104.

Ermida, Ó. (2012). Crítica de la libertad sindical. Derecho PUCP, (68), 33-61.

Ferrajoli, L. (2004). Derechos y garantías: la ley del más débil. Trotta.

Ferrajoli, L. (2008). Democracia y garantismo. Trotta.

Ferrajoli, L. (2013a). Principia iuris. 1. Teoría del derecho. Trotta.

Ferrajoli, L. (2013b). Principia iuris. 2. Teoría de la democracia. Trotta. 
Ferrajoli, L. (2013c). Principia iuris. 3. La sintaxis del derecho. Trotta. Foucault, M. (2004). Nietzsche, la genealogía, la historia. Pre-Textos. Fukuyama, F. (1990). ¿El fin de la historia? Estudios Públicos, (37), 5-31.

García Belaúnde, D. (1982). Los derechos humanos como ideología. Derecho PUCP, (36), 97-114.

González, R. (s. f.). Aproximaciones a los derechos humanos de cuarta generación. https://www.tendencias21.es/derecho/attach ment/113651/

Guastini, R. (2001). Estudios de teoría constitucional. Fontamara.

Hayek, F. (2006). Derecho, legislación y libertad. Unión Editorial.

Hierro, L. (2009). Los derechos económico-sociales y el principio de igualdad en la teoría de los derechos de Robert Alexy. En García, R. (ed.), Derechos sociales y ponderación (2. ${ }^{a}$ ed.) (pp. 163-222). Fundación Coloquio Jurídico Europeo.

Landau, D. (2015). Derechos sociales y límites a la reforma constitucional: la influencia de la jurisprudencia de la Corte Constitucional colombiana en el derecho comparado [ePub]. Universidad Externado de Colombia.

Marshall, T. H. (1997). Ciudadanía y clase social. Revista Española de Investigaciones Sociológicas, (79), 297-344.

Martínez, J. (2004). Las generaciones de derechos humanos. En Betegón, J., Laporta, F., Prieto, L. y De Páramo, J. (coords.), Constitución y derechos fundamentales (pp. 409-435). Centro de Estudios Constitucionales.

Nikken, P. (1994). El concepto de derechos humanos. En Cerdas, R. y Nieto, R. (comps.), Estudios básicos de derechos humanos. Tomo I (pp. 15-37). Instituto Interamericano de Derechos Humanos. 
Ortiz, L. (2008). El derecho de acceso a la justicia. En Becerra, M., Cruz, Ó., González, N. y Ortiz, L. (coords.), Obra en homenaje a Rodolfo Cruz Miramontes. Tomo II (pp. 403-422). Instituto de Investigaciones Jurídicas de la Universidad Nacional Autónoma de México.

Peña, A. (2016). La teoría fuerte de los derechos sociales: reconstrucción y crítica. Cuadernos Electrónicos de Filosofía del Derecho, (34), 251-269. https://ojs.uv.es/index.php/CEFD/article/ view/8262/8811

Pérez, A. E. (1991). Las generaciones de derechos fundamentales. Revista del Centro de Estudios Constitucionales, (10), 203-217.

Pisarello, G. (2007). Los derechos sociales y sus garantías. Trotta.

Prieto, L. (1995). Los derechos sociales y el principio de igualdad sustancial. Revista del Centro de Estudios Constitucionales, (22), 9-57.

Rabossi, E. (1997). Las generaciones de derechos humanos: la teoría y el cliché. Lecciones y Ensayos, (69-71), 41-52.

Rodríguez, C. (2015). La influencia de las clasificaciones de derechos humanos en la exigibilidad de los derechos económicos, sociales y culturales. Ciencia Jurídica, (7), 123-139.

Sánchez, D. (2011). Sobre el concepto de historización. Una crítica a la visión sobre las de-generaciones de derechos humanos. Praxis, (67), 9-22.

Vasak, K. (1977, noviembre). La larga lucha por los derechos humanos. El Correo de la UNESCO, 29-32. 